\title{
Agrotóxicos: a semente plantada no corpo e na mente dos trabalhadores rurais
}

Pesticides: a seed planted in the body and mind of rural workers

Plaguicidas: una semilla plantada en el cuerpo y en la mente de los trabajadores rurales

\author{
José Newton Garcia de Araújo* \\ Maria Regina Greggio** \\ Tarcisio Márcio Magalhães Pinheiro ${ }^{* * *}$
}

\begin{abstract}
Resumo
Este artigo discute uma experiência de assistência médica e psicológica a trabalhadores rurais, no Serviço Especializado em Saúde do Trabalhador (SEST), no Hospital das Clínicas da Universidade Federal de Minas Gerais. Essa experiência baseou-se no modelo de intervenção e pesquisa interdisciplinares, envolvendo equipes de Medicina do Trabalho e Psicologia do Trabalho. Os sujeitos assistidos apresentavam, em muitos casos, sintomas difusos de adoecimento físico e mental que podem estar associados tanto aos efeitos do contato com agrotóxicos quanto às condições precárias de trabalho e à vulnerabilidade psicossocial em que vivem. Tais sintomas podem ser compreendidos no quadro dos transtornos mentais menores ou da "síndrome geral de fadiga nervosa", por meio da qual Le Guillant (2006) estudou os nexos entre processos de trabalho e adoecimento. Com base em algumas teorias clínicas do trabalho, são discutidos alguns fragmentos dos casos acompanhados no SEST.
\end{abstract}

Palavras-chave: Trabalhadores rurais. Adoecimento mental. Medicina do trabalho. Psicologia do trabalho. Trabalho interdisciplinar.

\begin{abstract}
This article discusses an experience of medical and psychological treatment of rural workers, in the Specialized Service on Occupational Health (Serviço Especializado em Saúde do Trabalhador - SEST) of Hospital Clinics, Federal University of Minas Gerais. That experience was based upon a model of interdisciplinary intervention and research,
\end{abstract}

\footnotetext{
Professor dos cursos de graduação e pós-graduação da PUC Minas, psicólogo. E-mail: jinga@uol.com.br

** Mestra em Psicologia pela PUC Minas, coordenadora do Cerest Contagem-MG, psicóloga. E-mail: mareggio@gmail.com

${ }^{* * *}$ Doutor em Saúde Coletiva, professor da Faculdade de Medicina da UFMG, Belo Horizonte-MG. E-mail: tmmp@ medicina.ufmg.br
} 
involving medical groups of work medicine and work psychology. The individuals treated often pointed out diffuse symptoms of physical and mental illnesses, supposedly associated with effects of contact with pesticides and to their poor working conditions, besides the psychosocial vulnerability of their lives. Such symptoms can be included in the frame of "minor mental disorders" or of the "general syndrome of nervous fatigue", through which Le Guillant (2006) studied the links between working process and illness incoming. Some fragments of the cases treated in the SEST are discussed, based upon some theories of work clinics.

Keywords: Rural workers. Mental illness. Work Medicine. Work Psychology. Interdisciplinary work.

\section{Resumen}

En este artículo se analiza una experiencia de asistencia médica y psicológica a trabajadores rurales en el Servicio Especializado en Salud del Trabajador (SEST), en el Hospital de la Universidad Federal de Minas Gerais. Esta experiencia se basa en el modelo de intervención e investigación interdisciplinar, con la participación de equipos de medicina laboral y psicología laboral. Los sujetos atendidos presentaban, en muchos casos, síntomas difusos de enfermedades físicas y mentales que pueden estar asociados tanto con los efectos del contacto con pesticidas como con las malas condiciones de trabajo y la vulnerabilidad psicosocial en las que viven. Estos síntomas pueden ser entendidos en el contexto de los trastornos mentales leves o del "síndrome general de fatiga nerviosa”, a través del cual Le Guillant (2006) estudió la relación entre los procesos de trabajo y las enfermedades. Con base en algunas teorías clínicas del trabajo, se analizan algunos fragmentos de los casos tratados en el SEST.

Palabras clave: Trabajadores rurales. Enfermedad mental. Medicina del trabajo. Psicología del trabajo. Trabajo interdisciplinar.

$\mathrm{N}$ este texto, pretende-se abordar uma experiência de acompanhamento psicológico a trabalhadores rurais, atendidos no ambulatório que sedia o Serviço Especializado em Saúde do Trabalhador (SEST), no Hospital das Clínicas da UFMG. Esse serviço ambulatorial reúne residentes em Medicina do trabalho e docentes-preceptores do Departamento de Medicina Preventiva e Social da UFMG, além de uma equipe multidisciplinar que 
envolve psicólogos, fisioterapeutas, terapeutas ocupacionais, fonoaudiólogos, além de outras especialidades médicas, convocadas em caso de interconsultas. A equipe de Psicologia foi integrada a esse serviço, atendendo a uma demanda de sua coordenação, dada a verificação de problemas mentais entre os trabalhadores rurais que buscavam o serviço. Esses sujeitos apresentavam queixas inespecíficas e sintomatologia difusa, num quadro de mal-estar físico e psíquico generalizado. Exceto alguns casos de distúrbios mentais severos, eles eram portadores de um sofrimento análogo àquele que Le Guillant denomina morbidade psiquiátrica difusa (Lima, 2006), referindo-se à ocorrência crescente, já na década de 1950, de distúrbios mentais ou nervosos "de menos importância”, observados em telefonistas e mecanógrafas. Em seu célebre estudo "A neurose das telefonistas", Le Guillant definia tal sofrimento como parte de uma "síndrome geral da fadiga nervosa, ao mesmo tempo corrente e muito mal conhecida - embora, neste caso concreto, mais manifesta" (Lima, 2006, p. 176).

Psiquiatra e um dos precursores das atuais correntes conhecidas como "clínicas do trabalho" (Psicodinâmica do Trabalho, Clínica da Atividade, Ergologia, Psicossociologia do Trabalho), Le Guillant já mencionava, no caso das telefonistas, o nexo entre tal síndrome e "a própria natureza de suas atividades profissionais" (Lima, 2006, p. 175).

Suas observações sobre as telefonistas se aproximam, pois, quanto à sintomatologia vaga, do sofrimento difuso constatado entre os trabalhadores rurais atendidos no SEST, embora tal quadro possa se aplicar a numerosas outras categorias de trabalhadores. Ao afirmar que tais sintomas remetem a uma "síndrome subjetiva comum", ele reitera a relação íntima entre a fadiga nervosa e o contexto laboral, aí introduzindo a dimensão da subjetividade, nos planos individual e coletivo. Le Guillant contesta ainda as interpretações que pretendem reduzir o sofrimento a problemas psíquicos endógenos, o que anularia os nexos entre trabalho e adoecimento psicossomático:

Trata-se de um quadro polimorfo, formado por uma sintomatologia rica e variada, em que é possível encontrar, de uma maneira constante e sobreposta em todos os sujeitos, determinados distúrbios predominantes. Pode-se estabelecer a sistematização aproximada desses distúrbios, descrevendo essencialmente: uma "síndrome subjetiva comum" de fadiga nervosa; alterações do humor e do caráter; distúrbios do sono; um conjunto de manifestações somáticas variáveis; a repercussão destes diferentes distúrbios sobre a vida das empregadas (Lima, 2006, p. 177). 
Estima-se que há poucas pesquisas, na área da Psicologia, sobre a saúde mental do trabalhador rural no Brasil. Segundo Albuquerque (2002), são as cidades que demandam uma aplicação imediata da Psicologia, por concentrarem grandes empresas, bolsões de miséria, problemas ligados à marginalização, delinquência e outros. Por isso as metodologias e instrumentos psicológicos são baseados e pensados para a população urbana. No entanto, além do trabalho acima citado, já podemos encontrar algumas pesquisas, principalmente na área da Psicologia social e da saúde mental, dirigidos à população rural, tais como Faker (2009); Favero e Sarriera (2009); Vasquez (2009); Guimarães (2010); Araújo, Pinheiro e Greggio (2011); Moreira (2012), entre outras.

No entanto, é no campo da Medicina que encontramos estudos pioneiros ligados à saúde mental do trabalhador rural, nos quais são relatados tanto o grande índice de suicídios quanto a alta ocorrência de problemas mentais, associados ao uso generalizado de drogas psiquiátricas, nesta população. Citemos como exemplo: Possas e Trapé (1983); Rozemberg (1994); Faria, Facchini, Fassa e Tomasi (1999); Levigard e Rozemberg (2004); Meneguel, Victora, Faria, Carvalho e Falk (2004); Pires, Caldas e Recena (2005); Meyer, Resende, Abreu (2007).

O perfil de adoecimento desses trabalhadores configura um desafio clínico nos casos de transtornos mentais, pois estes costumam ter relação com outras patologias de origem laboral. Estas são, muitas vezes, decorrentes de intoxicação por produtos agrotóxicos. No entanto se devem também a fatores associados a acidentes de trabalho leves ou graves, bem como à organização e às condições precárias do trabalho no campo. Considere-se também que os problemas psicológicos remetem à singularidade de cada trabalhador, a eventuais estruturas neuróticas ou psicóticas que costumam emergir ou agravar-se por causa das condições adversas do trabalho rural.

Rozemberg (1994) sugere que as "doenças dos nervos" da população rural traduzem uma síndrome, dados os limites nebulosos entre o normal e o patológico. Aí nos defrontamos, de um lado, com a existência do "doente crônico", em se tratando de sofrimento mental ou de distúrbios psíquicos inespecíficos; de outro lado, com a dificuldade em se compreender ou mesmo diagnosticar as causas desse sofrimento.

Possas \& Trapé (1983) comentam que os casos crônicos desses pacientes se manifestam, do ponto de vista orgânico, por queixas como cefaleia difusa, malestar geral, epigastralgia, inapetência, etc. Em relação aos transtornos mentais, esses autores evitam uma análise puramente psicológica ou psiquiátrica dos 
casos, associando-os justamente ao contexto sociolaboral, especialmente nos agravos decorrentes da intoxicação crônica por herbicidas e inseticidas.

Ante a evidência dos casos crônicos de queixas associadas a uma sintomatologia vaga, Faria et al. (1999) os situam entre os "transtornos psiquiátricos menores" ou "morbidade psiquiátrica menor". Esses autores reafirmam que tal morbidade está associada à intoxicação por agrotóxicos, daí advindo sequelas neuropsicológicas persistentes, sejam elas moderadas ou agudas, embora observem que ainda são escassas as conclusões relativas aos efeitos psicológicos de longo prazo em pessoas com exposição crônica aos pesticidas.

A esse respeito, vale lembrar o que está afirmado no "Protocolo de Atenção à Saúde dos Trabalhadores Expostos a Agrotóxicos”, do Ministério da Saúde:

Os agrotóxicos podem causar diversos efeitos sobre a saúde humana, sendo muitas vezes fatais. Classicamente, tais efeitos são divididos em intoxicação aguda e intoxicação crônica. Além das intoxicações agudas, a exposição ocupacional e/ou ambiental também pode causar uma série de problemas de saúde, conhecida como intoxicação crônica. Estas podem se manifestar de várias formas, tais como: problemas ligados à fertilidade, indução de defeitos teratogênicos e genéticos, câncer, conforme foi revisto por Matos e colaboradores (1987). Também são relatados efeitos deletérios sobre os sistemas nervoso, respiratório, cardiovascular, geniturinário, gastrointestinal, pele, olhos, além de alterações hematológicas e reações alérgicas a estas substâncias (Ministério da Saúde, 2006).

\section{Entre a patologia e anormalidade}

Nos casos acompanhados no SEST/HC/UFMG, a maioria das queixas dos trabalhadores rurais remete à sintomatologia difusa, acima citada. No entanto, perguntamo-nos se essas síndromes, vistas como transtornos mentais menores, devem ser tratadas como uma patologia, em oposição a estados psíquicos supostamente normais.

Não vamos retomar aqui o debate sempre atual que, no campo das ciências humanas e sociais, discute os fundamentos científicos e, sobretudo, ideológicos que instituem a separação entre o normal e o patológico, questão esta levantada, entre outros, por autores como Canguilhem (1982) e Foucault (1975, 1977). No campo específico das doenças mentais associadas ao trabalho, lembremos as investigaçôes de Dejours (1987) inicialmente filiadas 
à corrente psiquiátrica da "psicopatologia do trabalho". Seu primeiro livro publicado no Brasil, em 1987, leva o título questionável de "A loucura do trabalho: estudos de psicopatologia do trabalho". ${ }^{1}$ Não por acaso, esse autor buscou a "normalidade", ao investigar como os trabalhadores conseguem evitar a sintomatologia da doença mental, mesmo sob fortes pressões organizacionais. Assim, para assegurar sua "normalidade", o trabalhador cria estratégias defensivas individuais e coletivas, justamente para não sucumbir à loucura, diante do sofrimento no trabalho. Isso mostra "a engenhosidade do espírito humano quando se trata de resistir à adversidade". (Dejours, 2007, p. 20).

O autor situa a normalidade como um arranjo entre o sofrimento e as estratégias defensivas para enfrentar esse sofrimento. Isso inclui a análise dos motores psíquicos e sociais, individuais e coletivos que buscam dar sentido e valor ao sofrimento, buscando, inclusive, transformá-lo em prazer. Posteriormente, ao chamar seu método de psicodinâmica do trabalho, Dejours pretendeu situar suas investigações para além da psicopatologia, pois esta não abarcaria, segundo ele, todo o campo da clínica. A psicopatologia do trabalho continua inserida no campo da psicodinâmica do trabalho, no caso em que "as estratégias de defesa são comprometidas por um sofrimento que o sujeito não consegue contornar, tornando-se autodestrutivo” (Dejours, 2007, p. 21).

Separando-se da clássica Psicologia organizacional funcionalista, adaptativa e historicamente comprometida com os interesses do capital, os estudos sobre a Psicologia do trabalho têm inspirado um novo modelo de produção do conhecimento, tendo o seu foco no trabalhador. Essa corrente pode ser definida como "uma psicologia que tem como ponto central o estudo e a compreensão do trabalho humano em todos os seus significados e manifestações" (Lima, 1993, p. 53). Ela busca compreender como o trabalho pode ser fator de equilíbrio, mas também pode causar adoecimento. É nesse sentido que Clot (2006) analisa o sofrimento no trabalho, tendo como foco a noção de atividade, propondo um referencial teórico-metodológico a que ele denomina clínica da atividade. Para ele, o sofrimento estaria ligado

[...] a uma atividade contrariada e até reprimida, em outros termos, como um desenvolvimento impedido. Trata-se então de uma amputação do poder de agir que proíbe os sujeitos de dispor de suas ações, que não os deixa transformar seu vivido em recurso de vivência de uma nova experiência (Clot, 2006, p. 9).

\footnotetext{
Na verdade, a melhor tradução do título original, "Travail et usure mentale", seria algo próximo a "Trabalho e desgaste mental", pois usure tem os sentidos de enfraquecimento, corrosão, degradação, não propriamente de loucura.
} 
Para esse autor, o trabalho pode ser tanto como fator de adoecimento quanto de equilíbrio. $\mathrm{Na}$ verdade,

Não são raros os meios profissionais em que os trabalhadores permanecem prisioneiros de objetivos artificiais e, não obstante, os fazem seus e se apossam de sua própria ação, em contextos que se tornam patogênicos [...]. Mas as provas do trabalho podem ter um destino diverso desse "envenenamento" da atividade: o de compensaçóes reais por meio das quais aqueles que trabalham conseguem recuperar sua disponibilidade psicológica [...] que indicam a retomada do desenvolvimento individual e coletivo (Clot, 2006, p. 10).

No campo da Psicologia, no Brasil, os estudos sobre "saúde mental \& trabalho" têm voltado a atenção para os fatores de agravo à saúde mental. Inserida nesse campo, e com um olhar diferente da "Psicologia organizacional", ocupada tradicionalmente em adaptar ou moldar o trabalhador aos interesses das empresas, a "Psicologia do trabalho" tem uma preocupação central em investigar os nexos entre o sofrimento, os transtornos mentais e as atividades laborais, aí incluindo as condições, a organização e as relaçôes de trabalho. No entanto, essa Psicologia, em sua vertente clínica e política, busca também ajudar o trabalhador a assumir seu lugar de sujeito (individual e coletivo), no sentido de que ele se aproprie de seu fazer profissional, bem como de seu espaço político na organização, análogo ao seu espaço de cidadão, na esfera da polis.

\section{Saúde pública e transdisciplinaridade}

A presença de psicólogos atuando junto aos trabalhadores rurais, no SEST/ HC/UFMG, baseou-se numa abordagem transdisciplinar, o que implica desafios relativos, de um lado, à conjugação de saberes diversos, tais como a medicina do trabalho, a psiquiatria e outras especialidades médicas, a fisioterapia, além da própria Psicologia; de outro lado, ao fato de que os problemas clínicos estão essencialmente ligados a questôes econômicas e socioculturais, o que implica a multideterminação da doença e a insere no campo da saúde pública. Com efeito, a saúde do trabalhador rural se encaixa nas diretivas da saúde populacional, conforme estabelece o "Manual de procedimentos para os serviços de saúde" no documento intitulado "Doenças relacionadas ao trabalho" (Ministério da Saúde, 2001):

$\mathrm{Na}$ condição de prática social, as ações de saúde do trabalhador apresentam dimensões sociais, políticas e técnicas indissociáveis. 
Como consequência, esse campo de atuação tem interfaces com o sistema produtivo e a geração de riqueza nacional, a formação e preparo da força de trabalho, as questôes ambientais e a seguridade social (Ministério da Saúde, 2001, p. 17).

Tal orientação se aplica a todos os segmentos urbanos ou rurais em que se descortina a necessidade de um cuidado à saúde da população. Daí a pertinência de uma ação multidisciplinar, envolvendo os gestores da saúde pública, com açóes específicas voltadas para todos os usuários do sistema nacional de saúde. Considerando que, a partir da Constituição Federal de 1988, a saúde do trabalhador passa a ser uma área de competência do Sistema Único de Saúde (SUS), as políticas dirigidas a esse setor, mesmo constatadas suas deficiências, encaixam-se nas propostas do Ministério de Saúde, como consta do mesmo manual acima citado:

Assim, frequentemente, as análises da situação de saúde, elaboradas em âmbito nacional, estadual ou municipal, limitamse à avaliação do perfil de morbimortalidade da população em geral, ou de alguns grupos populacionais específicos, mas as informações disponíveis não permitem a adequada caracterização das condições de saúde em sua relação com o trabalho, nem o reconhecimento sistemático dos riscos ou o dimensionamento da população trabalhadora exposta. Essas deficiências impedem o planejamento de intervençôes, sendo ainda isolados os estudos sobre a situação de saúde de trabalhadores em regiōes específicas (Ministério da Saúde, 2001, p. 21).

\section{O contexto socioeconômico dos sujeitos atendidos}

Voltemos aos trabalhadores rurais assistidos no SEST/HC/UFMG, em especial àqueles que se ocupam de atividades agropecuárias, em culturas tradicionais hortigranjeiras (tomate, pimentão, jiló e outras), geralmente distribuídas em pequenas propriedades, na base da agricultura familiar. Lembremos que os pequenos proprietários, com poucos recursos tecnológicos, longe de estarem desaparecendo do cenário produtivo nacional, são responsáveis por $70 \%$ do alimento que sustenta o mercado interno brasileiro, pois as grandes propriedades dirigem sua produção, geralmente monoculturas como soja, milho, cana-de-açúcar, etc., para o mercado externo.

Os pequenos agricultores só incorporam precariamente as tecnologias utilizadas nas grandes explorações agrícolas ou hortigranjeiras. No entanto, com uma produção diversificada, eles preservam a paisagem rural e sua 
biodiversidade, oferecendo fontes alimentares de qualidade, além de garantir, mesmo em condições precárias, seu trabalho e a geração de renda.

Sabemos que a população rural no Brasil está sujeita a fatores adversos, tais como: eventos climáticos imprevisíveis, que podem comprometer as safras; a oscilação de preços dos produtos, gerando prejuízos e desestímulo ao cultivo; dificuldades para a obtenção de financiamentos; a convivência permanente com os riscos de adoecimento ou acidentes, em especial no manejo de implementos/máquinas e no uso indiscriminado de agrotóxicos, em condições inseguras e sem o treinamento necessário para a sua utilização. Essas observações são retomadas por Lino (1992), no contexto das relações entre as políticas governamentais e os modelos de agricultura praticados em nosso País:

O modelo agrícola adotado no Brasil na década de 60 abriu mão da soberania da terra e da integridade do trabalhador rural, adotando um modelo de desenvolvimento insustentável em termos de custo social e ambiental. O setor rural no país caracterizase pela concentração fundiária, com intensiva mecanização e indiscriminada utilização de agrotóxicos, sem controle algum e sem que os trabalhadores tenham um minimo de informação sobre seu conteúdo. (grifos nossos) (Lino, 1992, p. 44)

\section{Discussão de casos}

Como dissemos acima, vários trabalhadores rurais atendidos no SEST/ HC/UFMG apresentam um quadro de sofrimento mental difuso, que poderíamos chamar, conforme seu linguajar, de "doenças dos nervos" ou, segundo Le Guillant, de "síndrome geral de fadiga nervosa” (Lima, 2006), pois suas queixas são difusas ou inespecíficas (Rozemberg, 1994), o que também poderia remeter aos "transtornos psiquiátricos menores" (Faria et al.,1999). No entanto, foram também acolhidos sujeitos com distúrbios mentais severos, os quais não relataremos aqui, especialmente porque os diagnósticos ficaram inconclusos e porque não era tão evidente sua relação com o trabalho.

Para comentar alguns desses casos, vamos nos ater a anotações retiradas de prontuários e das discussóes em equipe, dentro da perspectiva transdisciplinar. Em alguns casos, os diagnósticos ficaram a meio caminho, devido à interrupção do tratamento por parte de alguns sujeitos. Contudo julgamos que a maioria dos casos acompanhados fornecem pistas claras para associarmos os sofrimentos somáticos e psíquicos aos contextos laborais e psicossociais que envolvem o cotidiano desses trabalhadores. Em outras 
palavras, os problemas laborais não se reduzem à questão do contato com agrotóxicos, mas às condições gerais do trabalho enredadas com problemas familiares e com a situação socioeconômica precária desses sujeitos.

Apresentamos, a seguir, alguns fragmentos de cinco casos, três homens e duas mulheres, que permitem ilustrar, mesmo que apenas parcialmente, o contexto laboral e psicossocial do adoecimento.

Natanael (nome fictício, assim como os demais citados a seguir) diz que sempre gostou de trabalhar na roça, mas agora tem medo do agrotóxico: "lá não tem jeito de trabalhar sem veneno". Trabalhou em lavoura desde os 7 anos, com mais 15 irmãos, em propriedade da família. Aos 19 anos, empregou-se numa fazenda, cuidando de gado e roçando pasto. Depois passou à plantação de tomate, tendo contato direto com os agrotóxicos. Antes não usava os EPIs (equipamentos de proteção individual), mas agora os usa. No entanto, às vezes, está com pressa e não os coloca da forma apropriada. Sua queixa é o "problema de nervo". Diz que passou a tomar remédio controlado e que emagreceu bastante. Afirma que, nos últimos meses, melhorou um pouco, mas que "tá difícil trabalhar, ainda estou nervoso e fico cansado à toa".

Ananias relata que trabalha na lavoura desde menino, mas fez vários outros serviços para ganhar dinheiro e ajudar a família. Ficou exposto a agrotóxicos por aproximadamente 12 anos, aplicando-os com bomba de pulverização. Diz que não usa EPIs. Atualmente não está conseguindo trabalhar, mas antes "fazia o trabalho do dia todo em três horas e sempre bem feito". Julga-se tímido e afirma que começou a beber "para relaxar, conversar e dançar". Teve muita dificuldade para elaborar o luto pela morte do pai. Seu relatório médico consta de diagnóstico de hérnia discal e hepatotoxidade por agrotóxico. Foi afastado pelo INSS durante atendimento no SEST. Após seis meses de afastamento, diz que não tem vontade de voltar para o trabalho na lavoura. Queixa-se de dor na coluna e tonteira frequente e intensa. Relata alterações visuais, náuseas, vômitos, crises de ansiedade e, quando muito nervoso, sente contração e dor na região abdominal. "Sinto fraqueza nos nervos: dá suadeira, tremedeira e falta de ar, quando eu vou na horta, piora e eu sinto a vista turva. Às vezes sinto uma pontada no peito, minha cabeça dói constante". Relata que há mais ou menos um ano começou a ter sono agitado, não consegue dormir e fica cochilando o dia inteiro.

Misael trabalha em lavoura de tomate e conta que, dez anos atrás, sofreu um acidente de trabalho (não comunicado). Diz que a esposa é doente, que tem "problema de nervo, dá ataque de vez em quando e enrola a mão e os dedos". Relata que ele também já não está bem do nervo, pensou em beber veneno, 
mas refletiu que, "se minha esposa casasse de novo, o outro homem poderia maltratar a filha". Afirma que tem amigos, que gosta de sair com a filha, mas a esposa não gosta de ir junto. Diz que não tem mais esses "pensamentos de morte". Relata que, no dia em que usa agrotóxico, dorme muito mal e "a vista arde". Quando tem de usar "venenos mais fortes", sente enjoo e faz vômito. No dia a dia do serviço, às vezes, sente o fôlego acabar. Atualmente, sente-se mais cansado, desanimado e acha que é por causa da "pressão alta", confirmada pelo médico e atualmente controlada por medicação.

Madalena relata que começou a trabalhar na roça por volta dos 8 anos. Trabalha em lavoura própria, com o marido, mas, quando não dá pra viver só dela, trabalha para outros proprietários. Já foi também empregada doméstica durante dois anos. Antes, aplicava agrotóxico com pulverizador costal e bomba de pulverização. Atualmente, tem contato apenas indireto com agrotóxico: "não aplico, mas estou sempre colhendo e plantando onde ele foi jogado". Trabalha todos os dias, de 9 da manhã até 17 , inclusive aos domingos, mas só até a hora do almoço. Faz todos os serviços domésticos de sua casa. Levanta-se às 7 horas e não sabe dizer a que horas vai dormir, "só quando acaba o serviço de casa". Gostaria de ter tempo de passear, mas precisa trabalhar. Queixa de dores de cabeça, frigidez, incapacidade de sentir prazer (anedonia) e sensação de cansaço contínuo. Tais sintomas começaram mais ou menos dois anos antes da consulta. Diz que começou a sentir piora, havia cerca de dois meses, a ponto de quase ficar impossibilitada de trabalhar.

Judite foi diagnosticada com intoxicação por agrotóxicos e teve um acompanhamento mais prolongado, embora interrompido, depois de dois anos de tratamento. Sua demanda inicial era saber se estava intoxicada com agrotóxicos, pois soube que isso teria consequências graves, como câncer ou "problema de cabeça". Ela trabalha em lavoura própria, plantando tomate, pimentão, milho, feijão, morango. Ajuda o marido a preparar os agrotóxicos, aplicando-os, há mais ou menos nove anos, no mínimo três vezes por semana. Diz que não usa EPIs. Suas queixas iniciais eram insônia, zumbido, irritabilidade constante e falta de apetite. No decorrer do tratamento, acrescenta várias outras: tonteira e tremores, dor de cabeça e "nervo", fraqueza generalizada, perda de peso, além de confusão mental, labilidade emocional, ansiedade, depressão e diminuição da libido. Seu diagnóstico médico é de um quadro clínico de intoxicação crônica por agrotóxico, enquanto o diagnóstico psiquiátrico é de transtorno de humor, depressão e neurastenia. Relatou ter sido agredida pelo marido, tendo de ser socorrida em hospital da cidade vizinha. Diz que tem medo de se intoxicar e morrer, e "meus meninos ser criados sem mãe igual eu fui". A relação com o marido piora, ao longo das 
consultas, e Judite diz não ter como recorrer à assistência social ou a outros profissionais em sua cidade. Mas admite que o casal se agride mutuamente. Um mês depois de sua última consulta, soubemos, por outros trabalhadores rurais, que ela havia esfaqueado o marido, que passou várias semanas internado.

\section{Comentários}

Nestes cinco casos, temos uma espécie de pano de fundo comum, ou seja, as condições materiais de vida nas quais o trabalho rural quase se confunde com o trabalho doméstico e demais atividades do cotidiano, enfim, com a totalidade da vida da pessoa, configurando um só contexto do qual emergem problemas diversos que sugerem nexos diretos ou indiretos com as queixas somáticas e psíquicas acima apontadas.

Embora esses fragmentos de casos não reflitam a complexidade da história pessoal, familiar e laboral de cada sujeito, seu sofrimento e sua vida precária evocam fatores como: trabalho infantil na roça, na propriedade familiar ou como empregados; acúmulo de tarefas na lavoura e tarefas domésticas; exposição a agrotóxicos, impactos recíprocos (negativos) entre as dificuldades socioeconômicas e as relaçôes familiares. Ajuntemos ainda: precariedade da formação escolar e técnico-profissional; carência de vida cultural e isolamento social; falta de perspectiva, em termos de realização pessoal e de ascensão social; falta do próprio sentido de existir. Daí um sentimento generalizado de impotência, algumas vezes manifestado por meio de violência nas relaçôes familiares, assim como no alcoolismo, nos quadros depressivos e nos sintomas psicossomáticos mais diversos, traduzidos como "doença dos nervos".

Nesse contexto, parodiando Le Guillant, poderíamos falar de uma "síndrome geral de precariedade", que reflete, a um só tempo, carências de ordem financeira, sociocultural, educacional, técnico-profissional, psicoafetiva, enfim, existencial. Ela supõe uma somatória de cargas físicas e psíquicas, acumuladas desde a infância, ligadas ao trabalho na lavoura, aos problemas familiares e às demais carências decorrentes de políticas públicas relativas à valorização do pequeno agricultor.

Em síntese, os sintomas difusos ou inespecíficos, apresentados pelos sujeitos acima, remetem à acumulação de problemas laborais e psicossociais: de um lado, a exposição a agentes ambientais nocivos; de outro, o desgaste físico e mental, dadas as condiçóes de trabalho e as demais carências materiais e simbólicas. Ora, por mais que esses 
trabalhadores tentem se preservar, do ponto de vista da saúde física e psíquica, seus esforços têm um limite, dando lugar a sintomas que passam a traduzir a "fadiga geral" acumulada no corpo e no psiquismo. Podemos então compreender as queixas difusas ou inespecíficas como um duplo sentimento de impotência dos sujeitos. O primeiro consiste em enfrentar o conjunto de carências (financeiras, técnicas, socioafetivas, políticas), típicas das populaçôes de baixa renda; o segundo se liga à incapacidade de nomear, identificar ou problematizar a dor física e o sofrimento psíquico: “o que é mesmo que eu tenho?", "isso tem cura?", "vou contrair câncer ou outras doenças?". A esse respeito, Costa (1989) comenta:

As queixas constantes de mazelas físicas mostram que o corpo é um instrumento de comunicação fundamental do conflito psíquico, porque é investido culturalmente como a faceta mais representativa do sujeito. [...] Para todo ser humano a imagem corpórea é a matriz do ego. [...] Entre a imagem do corpo-prazer e a imagem do corpo-trabalho há um fosso importante. [...] As mulheres, mas, sobretudo os homens das camadas populares, utilizam o corpo para manifestarem o que não vai bem na identidade-trabalhadora. (Costa, 1989, p. 36).

$\mathrm{Na}$ ótica psicossocial e multidisciplinar, a "doença dos nervos" remete, entre outras coisas, à distância entre: a) sentir, experimentar dor ou mal-estar difuso; b) não saber o que se sente, especialmente quando as patologias orgânicas claramente diagnosticadas se manifestam por meio de sintomas difusos: além das dores osteomusculares, esses trabalhadores citam: insônia, sudorese, fraqueza, palpitações, problemas gástricos, tonteiras, dores de cabeça, entre outros. A multiplicidade dessas patologias impede o trabalhador de "localizar" sua doença e de, se tivesse meios, de combatê-la; c) a impotência para sair desse quadro de sofrimento, por falta de recursos próprios, pela ausência de proteção ou da assistência pública a que tem direito, assim como pela falta de perspectiva de uma ação coletiva que possa reverter essa situação de vulnerabilidade. Daí os quadros de depressão ou de angústia, o alcoolismo, a frigidez, os conflitos e violências conjugais, o desejo de autoextermínio ou sua efetivação.

$\mathrm{O}$ que nos interessa mais nesses casos é discutir o contexto social do aparecimento da chamada doença mental. Com efeito, esta não seria apenas um distúrbio "dentro" do sujeito (genético, hereditário), sem 
nenhuma relação com o "fora". Costa (1989, p. 18) comenta que "os distúrbios mentais só existem através de conflitos subjetivos, os quais, por seu turno, estão socioculturalmente condicionados". Assim, as "doenças nervosas" relatadas no cotidiano do trabalhador rural, mostram o elo entre as queixas individuais, a organização do trabalho e as tensões sociais. Daí a necessidade de contextualizarmos suas queixas, de conhecermos sua história e a realidade em que estão inseridos. Lembremos ainda as considerações de Le Guillant que reitera

[...] a unidade indissolúvel do indivíduo e do meio - unidade histórica, evidentemente dialética - é a lei fundamental, à qual não pode escapar o psiquismo normal ou doente, nem o próprio paciente inteiro. Nesta concepção, além disso, o psiquismo é o reflexo da realidade - sem dúvida, reflexo imperfeito - realizado de forma aproximada, mas composto unicamente pelos elementos da realidade. (Lima, 2006, p. 41).

\section{Conclusão}

Julgamos que o trabalho desenvolvido no SEST/HC/UFMG nos permitiu avançar nas metodologias de atendimento aos trabalhadores rurais com queixas ligadas às "doenças dos nervos". Essa expressão popularizada do sofrimento mental não é gratuita, pois as atividades em ambientes insalubres, além do contato com agrotóxicos e das condições de precariedade psicossocial, podem causar danos à saúde mental, tendo como consequência, entre outras, a alteração de comportamento.

Lembremos, no entanto, que esses trabalhadores não são apenas um organismo passivo aos efeitos dos agentes ambientais danosos. Eles são sujeitos em interação com seus pares ou com seus grupos de pertencimento, tentando encontrar coletivamente, mesmo que por caminhos tortuosos, formas de enfrentar o adoecimento coletivo e individual, lutando "para dar sentido ao mundo, entendê-lo e nele encontrar seu lugar, através de uma identidade social" (Jovchelovitch, 1994, p. 65).

Nossa experiência mostra ainda que esses trabalhadores tentam interagir também com os profissionais da saúde, quando buscam o tratamento, quando falam de seu sofrimento, do contexto laboral e social em que o adoecimento é gerado. Ora, tal contexto é complexo e constitui um desafio aos profissionais da saúde do trabalhador, uma 
vez que esta supõe "uma visão da relação entre o trabalho e o processo de saúde doença que supera aquela do ambiente e seus agentes. Nela, o biológico e o psíquico interagem, constituindo um nexo psicofísico indissociável" (Centro de Referência Técnica em Psicologia e Políticas Públicas, 2010).

O enfrentamento do adoecimento gera, ao mesmo tempo, construções simbólicas coletivas. Tal é o caso da representação social do agrotóxico, considerado por alguns sujeitos, a justo título, como "veneno". Ao falar de representação social, é preciso entendê-la nos contextos históricos de sua construção. Com efeito, os agrotóxicos atravessam conflitivamente a vida do trabalhador rural. Se, de um lado, eles são um "veneno", de outro, são vistos como essenciais à lavoura: sem eles, dada a ausência de alternativas técnicas, não se pode competir no mercado, não se vende o produto do próprio trabalho, enfim, não é possível sobreviver. Daí as estratégias cotidianas desses sujeitos, suas resistências e a forma como lidam coletivamente com o adoecer.

No entanto, se os trabalhadores rurais convivem com os agrotóxicos, já há muitas décadas, é relativamente recente o seu acesso às informações sobre os riscos do contato com tais produtos. Daí a emergência de conflitos: como sobreviver sem o "trabalho que mata"? É possível produzir sem agrotóxicos? Em muitos casos, a impotência para enfrentar a situação, devido à situação de vulnerabilidade psicossocial, resulta no próprio adoecimento mental, que não pode ser isolado do contexto em que é produzido.

Em alguns casos, esse sofrimento pode chegar a extremos, como o impulso de autoextermínio (sabemos dos altos os índices de suicídio entre trabalhadores rurais). Em outras situações, o sofrimento pode desembocar na própria recusa ao trabalho, como no caso de Judite, que não queria retornar ao trabalho, com medo de contrair câncer ou "problema de cabeça".

Nesta conclusão sucinta e provisória, talvez nos reste reiterar que o atendimento aos trabalhadores rurais, no SEST/HC/UFMG e nos demais serviços de saúde do trabalhador, constitui um desafio que deve ser enfrentado por múltiplos saberes e olhares. A experiência de atendimento psicológico a esses sujeitos, junto a uma equipe transdisciplinar, é um passo inicial, uma tentativa de compreensão $\mathrm{da}$ complexa realidade que os envolve, realidade essa da qual tanto as patologias orgânicas por intoxicação quanto as patologias mentais são 
apenas alguns de seus componentes. Não se trata, pois, aqui, de apontar soluçôes, mas de mostrar nossa tentativa de produzir, a um só tempo, conhecimentos e práticas clínicas que possam, juntamente com políticas públicas adequadas, responder às necessidades desses trabalhadores, relativas ao seu acesso não apenas à saúde no trabalho, mas ao conjunto de fatores que lhes garantam os direitos de cidadania.

\section{Referências}

Albuquerque, F. J. B. (2002). Psicologia social e formas de vida rural no Brasil. Psicologia: Teoria e Pesquisa, 18 (1), 37-42.

Araújo, J. N. G. A., Pinheiro, T. M. M. \& Greggio, M. R. (2011). Notas sobre o adoecimento mental em trabalhadores rurais. In J. C. Zanelli, N. Silva, S. R. Tolfo (Org.). Processos psicossociais nas organizações e no trabalho. (pp. 49-60). São Paulo: Casa do Psicólogo.

Canguilhem, G. (1982). O normal e o patológico. Rio de Janeiro: Forense Universitária.

Centro de Referência Técnica em Psicologia e Políticas Públicas (2010). Diretrizes: saúde do trabalhador - apontamentos para a atuação profissional. Brasília: Conselho Federal de Psicologia.

Clot, Y. (2006). A função psicológica do trabalho. Petrópolis: Vozes.

Costa, J. F. (1989). Psicanálise e contexto cultural: imaginário psicanalitico, grupos e psicoterapias. Rio de Janeiro: Campus.

Dejours, C. (1987). A loucura do trabalho. São Paulo: Oboré.

Dejours, C. (2007). Prefácio. In A. M. Mendes (Org.). Psicodinâmica do trabalho: teoria, método e pesquisas (pp. 19-22). São Paulo: Casa do Psicólogo.

Faker, J. N. (2009). A cana nossa de cada dia: saúde mental e qualidade de vida dos trabalhadores rurais de uma usina de álcool e açúcar de MS. Dissertação de Mestrado, Pós-graduação em Psicologia, Universidade Católica Dom Bosco, Campo Grande. 
Faria, Neice M. X., Facchini, Luiz A., Fassa, Anaclaudia G. \& Tomasi, Elaine. (1999, agosto). Estudo transversal sobre saúde mental de agricultores da Serra Gaúcha (Brasil). Revista Saúde Pública, 33 (4), 391-400.

Favero, E. \& Sarriera, J. C. (2009). Extensão rural e intervenção: velhas questôes e novos desafios para os profissionais. Cadernos de Psicologia Social do Trabalho, 12 (1), 1-16.

Foucault, M. (1975). Doença mental e psicologia. (2a ed.). Rio de Janeiro: Tempo Brasileiro.

Foucault, M. (1977). A história da loucura na Idade Clássica. São Paulo: Perspectiva

Guimarães, M. C. (2010). Trabalho e dor na agricultura: análise ergonômica do arranquio de feijāo. Curitiba: Juruá.

Jovchelovitch, S. (1994). Vivendo a vida com os outros: intersubjetividade, espaço público e representações sociais. In P. Guareschi, S. Jovchelovitch (Orgs.). Textos em representaçôes sociais (pp. 63-85). Petrópolis: Vozes.

Levigard, Y. E. \& Rozemberg, B. (2004). A interpretação dos profissionais de saúde acerca das queixas de "nervos" no meio rural: uma aproximação ao problema das intoxicações por agrotóxicos. Cadernos de Saúde Pública, 20 (6), 1515-1524.

Lima, M. E. A. (1993). O psicólogo organizacional e sua inserção no contexto sociopolítico. Anais da Semana de Psicologia Política, 5 (pp. 97-109). Belo Horizonte: Departamento de Psicologia da UFMG.

Lima, M. E. A. (Org.). (2006). Escritos de Louis Le Guillant: da ergoterapia à psicopatologia do trabalho. Petrópolis: Vozes.

Lino, D. (1992, abril/maio). Meio ambiente e saúde e as condiçōes de trabalho. Revista INST, 8, 16.

Meneguel, S. N., Victora, C. G., Faria, N. M., Carvalho, L. A. \& Falk, J. W. (2004). Características epidemiológicas do suicídio no Rio Grande do Sul. Revista de Saúde Pública, 38 (6), 804-810.

Meyer, T. N., Resende, I. L. C. \& Abreu, J. C. (2007). Incidência de suicídio e uso de agrotóxicos por trabalhadores rurais em Luz (MG), Brasil. Revista Brasileira de Saúde Ocupacional, 32 (116), 24-30. 
Ministério da Saúde. (2001). Doenças relacionadas ao trabalho: manual de procedimentos para os serviços de saúde. Brasília: Ministério da Saúde.

Ministério da Saúde. (2006). Protocolo de atenção à saúde dos trabalhadores expostos a agrotóxicos. Brasília: Ministério da Saúde. Disponível em: http:// bvsms.saude.gov.br/bvs/publicacoes/protocolo_atencao_saude_trab_exp_ agrotoxicos.pdf

Moreira, L. M. F. (2012). Saúde do trabalhador e adoecimento psíquico: o atendimento clínico ao trabalhador rural. Dissertação de Mestrado, Programa de Pós-graduação em Psicologia, PUC Minas, Belo Horizonte.

Pires, D. X., Caldas, E. D. \& Recena, M. C. P. (2005). Uso de agrotóxicos e suicídios no Estado do Mato Grosso do Sul, Brasil. Cadernos de Saúde Pública, Rio de Janeiro, 21 (2), 598-605.

Possas, C. A. \& Trapé, A. Z. (1983). Saúde e trabalho no campo: da questão agrária à política previdenciária. Cadernos do Internato Rural, 2 (1/2), 13-19.

Rozemberg, B. (1994). O consumo de calmantes e o "problema de nervos" entre lavradores. Revista de Saúde Pública, 28 (4), 300-308.

Vasquez, G. C. F. (2009). A Psicologia na área rural: os assentamentos da reforma agrária e as mulheres assentadas. Psicologia, Ciência e Profissão, 29 (4), 856-867. 